\title{
Technical note: Infusion, sampling, and vacuum-assisted collection devices for use in ruminally cannulated calves
}

\author{
T. T. Yohe, ${ }^{*}$ H. Schramm, † C. L. M. Parsons, ${ }^{*}$ R. R. White, $\ddagger$ and K. M. Daniels*1 \\ *Dairy Science Department, \\ †Virginia Maryland Regional College of Veterinary Medicine, and \\ $\ddagger$ Animal and Poultry Science Department, Virginia Polytechnic Institute and State University, Blacksburg 24061
}

\section{ABSTRACT}

Calves can be ruminally cannulated at young ages, but equipment size limitations preclude use of an infusion and sampling device in these small animals. Likewise, a procedure to easily evacuate rumen contents in young calves has not been described. Overcoming these technical complications related to assessment of ruminal passage kinetics, nutrient digestion, and volatile fatty acid absorption would aid in future studies advancing our knowledge of dairy calf nutrition. The first objective was to design and fabricate 2 devices (one device for infusion and sampling, and another for vacuum-assisted collection) suitable for use in young ruminally cannulated dairy calves. The second objective was to test the utility of these tools when performing procedures commonly used in ruminant nutrition research. A single weaned 62-d-old ruminally cannulated calf was used to evaluate the ability to infuse a solution of LiCoEDTA and sample rumen contents through the cannula cap over a period of $2 \mathrm{~h}$ to assess the rumen liquid passage rate (procedure 1). The device was capable of infusing the LiCoEDTA and sampling the rumen fluid, as evidenced by the presence of elevated Co concentrations in the sampled rumen fluid. Using the fluid samples obtained, liquid passage rate within the calf was estimated to be $40.2 \%$ of ruminal fluid/h. The second procedure tested the vacuum-assisted collection device and consisted of evacuating and weighing the rumen contents, which is considered a key preparatory step in washed reticulorumen technique experiments that aim to measure nutrient absorption. In agreement with existing literature, evacuated rumen contents represented approximately $4 \%$ of the calf's body weight. In conclusion, custom-built devices for infusion, sampling, and vacuum-assisted collection were efficacious when tested in a 62 -d-old ruminally cannulated calf fed a diet

Received February 26, 2018.

Accepted May 22, 2018.

${ }^{1}$ Corresponding author: danielsk@vt.edu of $100 \%$ texturized starter ( $18 \%$ crude protein, as-fed). Fellow scientists may employ and further modify these techniques to suit their needs when assessing passage kinetics, nutrient digestion, and volatile fatty acid absorption in calves.

Key words: calf rumen cannulation, rumen evacuation, washed rumen technique, calf nutrition, passage rate

\section{Technical Note}

Ruminal passage kinetics (Azevedo et al., 2016), nutrient digestion, and VFA absorption (Conrad et al., 1956; Sutton et al., 1963; Khouri, 1969) are difficult to assess in young dairy calves. Overcoming technical complications related to assessment of ruminal passage kinetics, nutrient digestion, and VFA absorption are therefore essential steps toward improving our understanding of dairy calf nutrition.

In experiments that measure ruminal passage kinetics, nutrient digestion and VFA absorption in mature ruminants are often facilitated by use of ruminally cannulated animals. These animals are typically fitted with a specialized indwelling infusion and sampling device (Annison et al., 1974; Sutton et al., 2003) or a washed reticulorumen technique is employed, the latter requiring an evacuated rumen (Gaebel et al., 1987; Kristensen and Harmon, 2004; Storm et al., 2011). Calves can be ruminally cannulated at young ages (Lesmeister and Heinrichs, 2004; Kristensen et al., 2010; Suárez-Mena et al., 2015), but equipment size limitations preclude use of an infusion and sampling device in young calves. Likewise, an efficient means to easily evacuate rumen contents in young calves has not been described.

Our first objective was to design and fabricate an infusion and sampling device and a separate vacuumassisted rumen contents collection device suitable for use in young ruminally cannulated dairy calves. The second objective was to test the effectiveness of these devices in a ruminally cannulated calf. Two procedures common in ruminant nutrition research were selected to evaluate the performance of our newly created de- 
vices. The first procedure was to infuse a solution of LiCoEDTA into the rumen and sample rumen contents through the cannula cap over time to assess rumen liquid passage rate (Udén et al., 1980; Dijkstra et al., 1993; Krizsan et al., 2010). The second procedure was to remove and collect the content of the rumen, which is considered a key preparatory step in washed reticulorumen technique experiments that aim to measure nutrient absorption (Gaebel et al., 1987; Kristensen and Harmon, 2004; Storm et al., 2011).

Our device design approach for the infusion and sampling device was to identify important functional properties of systems used in mature animals and scaledown components using commercially available materials. Design elements of the vacuum-assisted rumen collection device feature an open-ended vacuum tube connected to a custom-built sanitary trap and commercial vacuum pump (Figures 1, 2, 3, and 4).

The design, manufacture, and evaluation of our 2 devices were conducted from September 2016 to November 2016. One Holstein bull calf born at Virginia Tech (VT) was used in the evaluation of the devices. It should be noted that only 1 calf was used due to the pilot trial nature of this study to test devices and techniques that will be used in future studies. The following procedures were approved by the VT Animal Care and Use Committee (protocol \#15-181). The bull calf was healthy (serum total protein $60 \mathrm{mg} / \mathrm{mL}$ after colostrum feeding) and underwent rumen cannulation surgery on d 5 of age. The rumen cannulation surgery was performed similarly to that described by Kristensen et al. (2010). The surgically placed rumen cannula (2.75 $\mathrm{cm}$ i.d.) was the same design used in Lesmeister and Heinrichs (2004) and Suárez-Mena et al. (2016). The cannula opening was plugged with a \#6 rubber laboratory stopper.

The calf was fed twice daily at 0700 and $1900 \mathrm{~h}$. Prior to weaning, the calf was fed a diet of milk replacer (Southern States Cooperative, Richmond, VA) containing $22 \% \mathrm{CP}$ and $20 \%$ fat (as-fed basis) and texturized calf starter (Southern States Cooperative) containing $18 \%$ CP (as-fed). Water was available at all times. The calf was housed in an individual calf hutch bedded with sawdust. Hay was not offered. The calf's birth weight was $43 \mathrm{~kg}$ and the calf weighed $80 \mathrm{~kg}$ on d 62 of life, which coincided with the procedures described

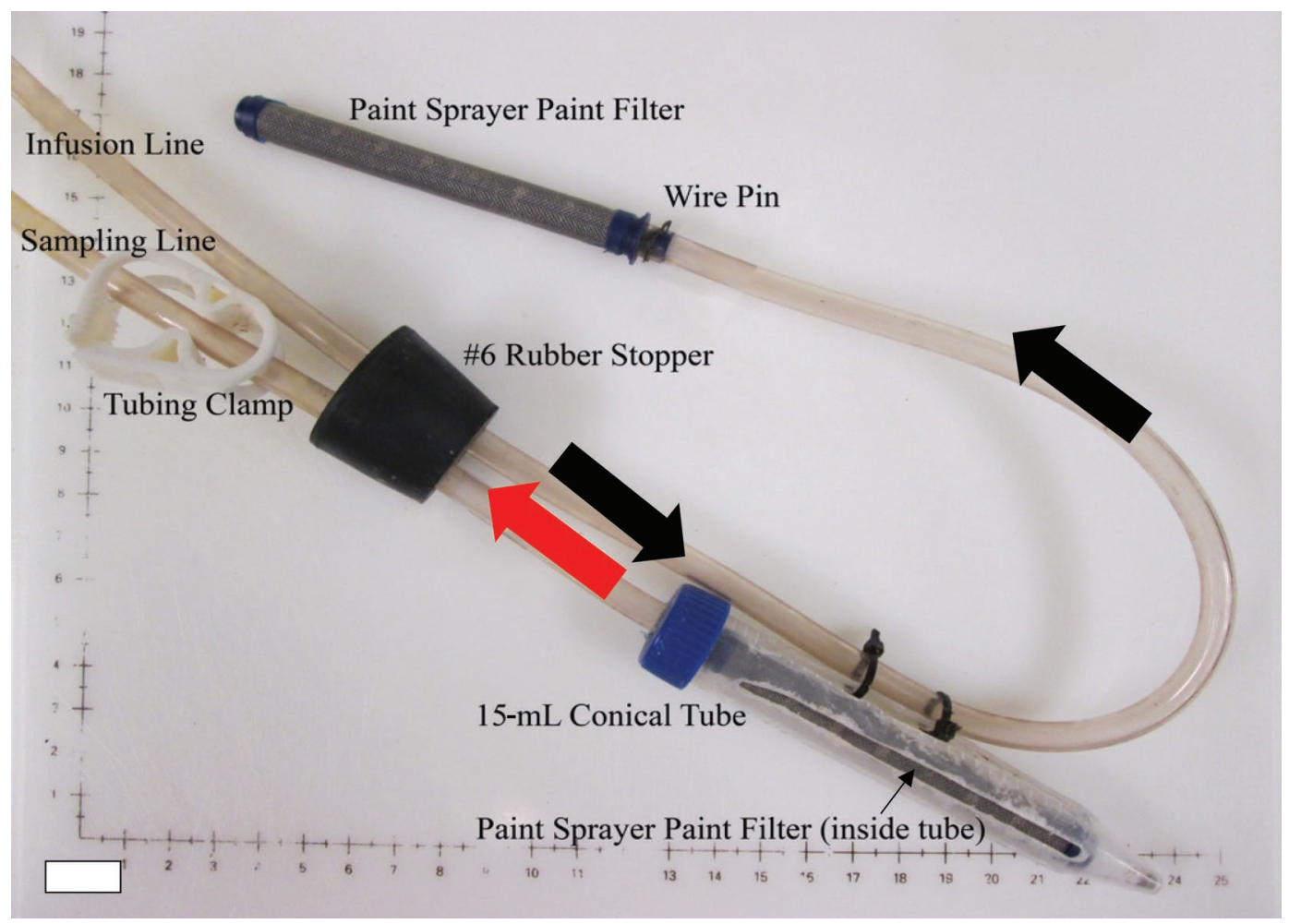

Figure 1. Custom-made rumen infusion (upper line) and sampling (lower line) device built and used to administer infusate and sample rumen fluid, respectively, in the ruminally cannulated calf. Infusion line connects to distal end of IV set and sampling line connects to a 60-mL syringe. Infusion and sampling lines were 145 and $28 \mathrm{~cm}$ in length, respectively, and both were $0.64 \mathrm{~cm}$ o.d. $\times 0.48 \mathrm{~cm}$ i.d. plastic tubing. See text for further specifications. Black and gray (red) arrows denote direction of fluid through infusion and sampling lines, respectively. White scale bar represents $2 \mathrm{~cm}$. Color version available online. 


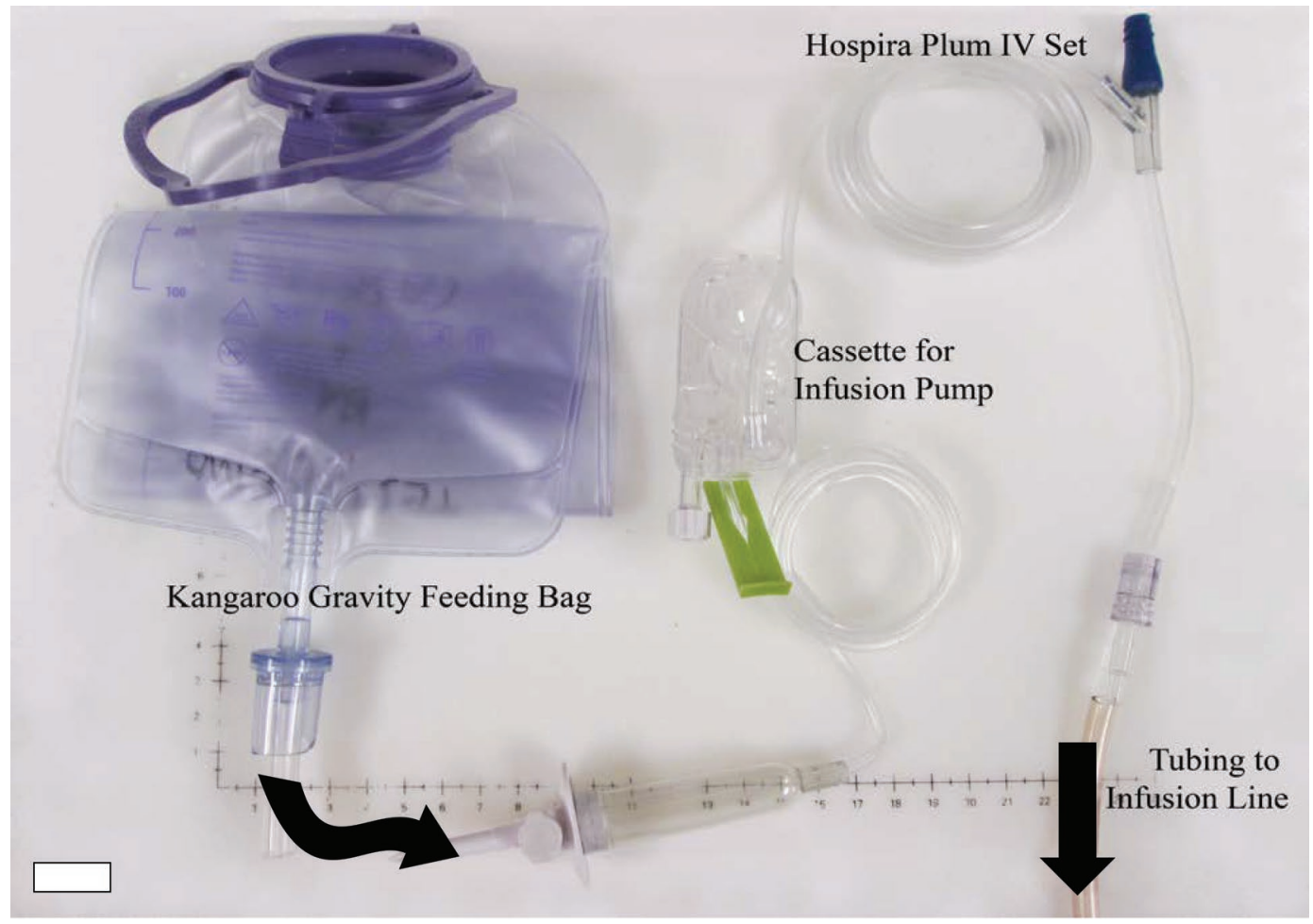

Figure 2. Modified rumen infusion bag and infusion line used to administer infusate in the ruminally cannulated calf. The Kangaroo gravity feeding bag (Covidien, Dublin, Ireland) is attached to the Plum IV set (Hospira, Lake Forest, IL). The infusion line was $145 \mathrm{~cm}$ in length and $0.64 \mathrm{~cm}$ o.d. $\times 0.48 \mathrm{~cm}$ i.d. plastic tubing. See text for further specifications. Black arrow denotes direction of fluid through infusion line. White scale bar represents $2 \mathrm{~cm}$. Color version available online.

next. The calf gained $0.597 \mathrm{~kg} / \mathrm{d}$, which agrees with NRC (2001) data for calves consuming milk replacer and starter with similar DMI (intake data not shown) gaining around $0.6 \mathrm{~kg} / \mathrm{d}$. On d 62 of life, immediately after the evening feeding, the calf was haltered and walked approximately $90 \mathrm{~m}$ to a $2.13 \mathrm{~m}$ long $\times 1.32 \mathrm{~m}$ wide pen in a nearby barn. The halter was tied off so the calf could lie down but not turn around. Drinking water and starter were available to the calf unless noted otherwise.

Our rumen infusion and sampling device (Figures 1 and 2) was adapted from similar devices used in mature dairy cows (Annison et al., 1974; Sutton et al., 2003). During use, the infusion and sampling device was manually guided into the ventral sac of the rumen. As shown in Figure 1, we used $0.64 \mathrm{~cm}$ o.d. $\times 0.48 \mathrm{~cm}$ i.d. plastic tubing for both the infusion line and the sampling line. Both lines were passed through a \#6 rubber laboratory stopper; this stopper acted as a cannula plug during the infusion and sampling period. The rumen content sampling line terminated into a paint sprayer filter (297- $\mu$ m filter; model no. 288749; Graco, Minneapolis, MN) shielded by a fenestrated $15-\mathrm{mL}$ plastic conical tube (Figure 1). Fenestrations were made using a rotary cutting tool (model no. 285, Dremel, Racine, WI).
This design feature filtered out large feed particles and prevented sampling lines from clogging. The infusion line was attached to the conical tube using cable ties to help maintain rigidity upon insertion. The infusion line was not contained in a fenestrated conical tube and also terminated in a paint sprayer filter $(297-\mu \mathrm{m}$ filter; model no. 288749; Graco; Figure 1). To permanently affix paint sprayer filters into plastic tubing, filters were inserted into the tubing and an electric drill was used to make holes through the filter collars and the tubing. Then, a small piece of flexible wire was inserted into each hole and bent (similar to a cotter pin). To lower the risk of accidental animal puncture, orthodontist's wax was applied to any exposed wire during use. An IV set (Primary PlumSet; Hospira, Lake Forest, IL) fed into the top of the electronic clinical infusion pump (Abbott Lifecare 5000; AIV, Harmans, MD) with the infusate (described later) contained within a 1-L Kangaroo gravity feeding bag (Covidien, Dublin, Ireland; Figure 2). The proximal end of the infusion line $(\sim 145$ $\mathrm{cm}$ in length) was joined to the distal line of the IV set. The free end of the sampling line $(\sim 28 \mathrm{~cm}$ in length) was clamped between sample collections (Figure 1). When a rumen fluid sample was taken, a $60-\mathrm{mL}$ syringe was attached to the free end of the sampling line 


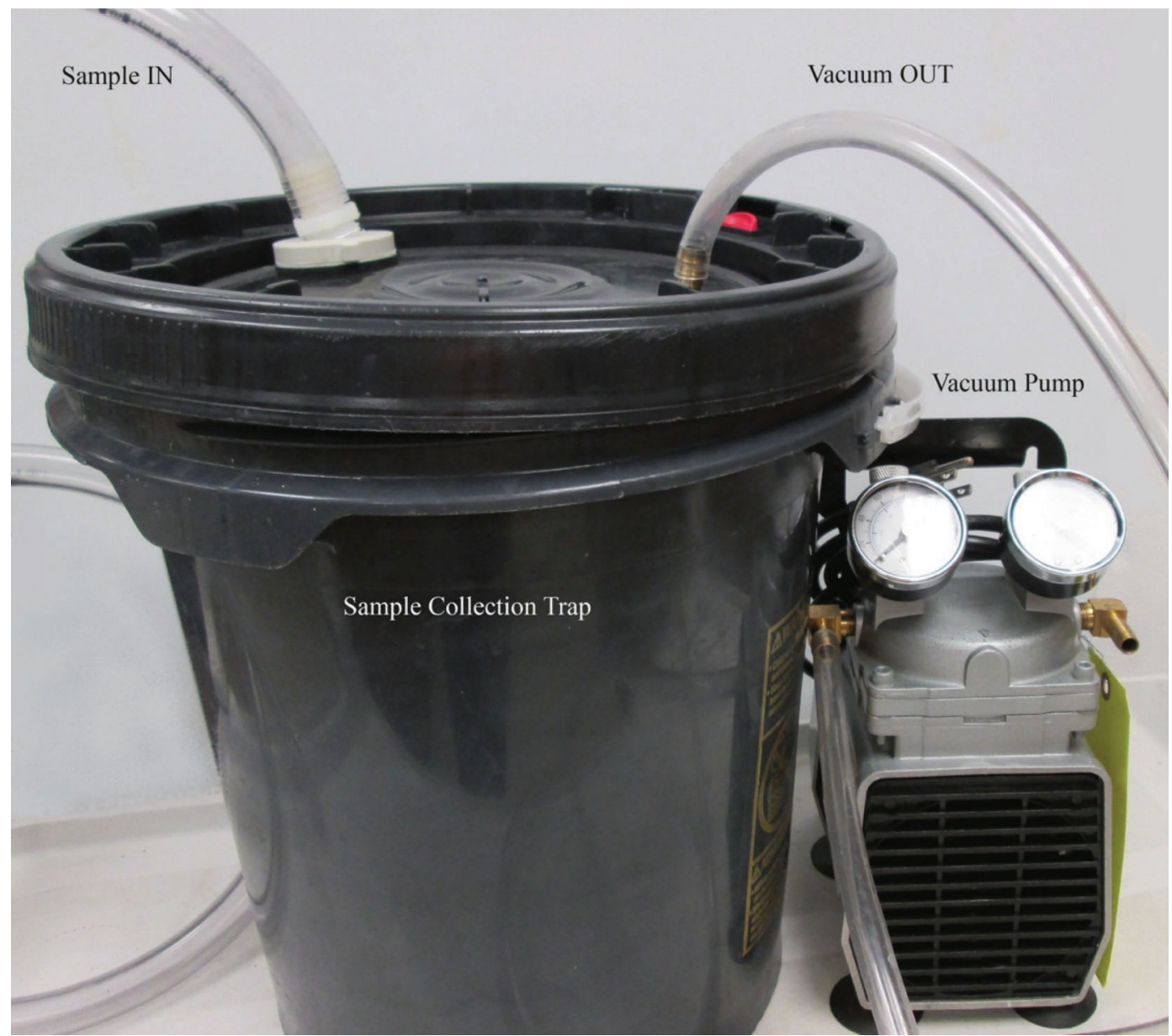

Figure 3. Fully assembled custom-made vacuum-assisted collection device (18.93-L bucket) used to suction rumen contents out of the rumen and temporarily store rumen contents. The sample in tube (vacuum tube) was $183 \mathrm{~cm}$ long and $2.54 \mathrm{~cm}$ o.d. $\times 1.91 \mathrm{~cm}$ i.d.; the vacuum out tube was $223 \mathrm{~cm}$ long and $1.27 \mathrm{~cm}$ o.d. $\times 0.87 \mathrm{~cm}$ i.d. See text for further specifications. Color version available online.

(Figure 1), the clamp was released, and the syringe was used to manually draw up rumen fluid. The first 5 to 10 $\mathrm{mL}$ (sample line dead volume) were discarded at each sampling.

In many rumen metabolism experiments, continuous infusion of a CoEDTA compound has been used to assess rumen liquid passage rate (Udén et al., 1980; Dijkstra et al., 1993; Krizsan et al., 2010). Thus, we rationalized that LiCoEDTA would be a suitable infusate for us to test with our rumen infusion and sampling device. The device would be considered a success if the infusate was recovered in all rumen fluid samples and the calculated rate of liquid passage considered plausible when compared with existing data for calves fed a similar diet. To assess rumen liquid passage rate, a continuous infusion of a LiCoEDTA solution $(0.45 \mathrm{mg}$ of $\mathrm{LiCoEDTA} / \mathrm{mL}$ ) was administered at a rate of $20 \mathrm{~mL} / \mathrm{h}$ starting approximately $8 \mathrm{~h}$ before sampling to bring the concentration of LiCoEDTA to a plateau (Krizsan et al., 2010). In our case, the LiCoEDTA infusion began at $0045 \mathrm{~h}$ and the first rumen fluid sample was collected at $0900 \mathrm{~h}$. The infusion pump was calibrated in our laboratory before use by setting the pump to dispense $20 \mathrm{~mL}$ of a LiCoEDTA aqueous solution over $1 \mathrm{~h}$. The volume and weight of the solution resulted in $20 \mathrm{~mL}$ and $20 \mathrm{~g}$ after $1 \mathrm{~h}$, respectively. Beginning at $0900 \mathrm{~h}$ on the day of the experiment, rumen fluid samples $(\sim 5$ to $10 \mathrm{~mL}$ ) were obtained through the sampling line every $15 \mathrm{~min}$ for $2 \mathrm{~h}$. Rumen $\mathrm{pH}$ of each sample was measured immediately (EcoSense pH100A Meter; YSI Inc., Yellow Springs, $\mathrm{OH}$ ), and the remaining samples were transferred to $15-\mathrm{mL}$ conical tubes and frozen at $-20^{\circ} \mathrm{C}$ until analysis. For analysis of LiCoEDTA these 8 samples underwent nitric acid digestion using method $3030 \mathrm{H}$ via EPA (1998). Cobalt determination was by inductively coupled plasma atomic emission spectroscopy completed at the VT Soil Testing Laboratory. In brief, samples were exposed to inductively coupled 
argon plasma, where temperatures reached $8,000^{\circ} \mathrm{C}$ and excited any element present. The light emitted from the excitation was collected and measured in the connected spectrometer where the intensity of the wavelength (228.616 $\mathrm{nm}$ for Co) was converted to a concentration of the corresponding element.

The Co results in Table 1 show that both the infusion and sampling method were successful. Further, over a 2 -h period, the rumen liquid passage rate equaled $40.2 \% / \mathrm{h}$. Because the system did not reach steady state (i.e., the concentration of Co did not plateau), a non-steady state solution was derived using a dynamic mechanistic model. A 2-pool model with entry and exit fluxes was constructed. The first pool represented the rumen fluid volume (L) and the second pool represented the Co mass (mg) within the rumen fluid. Entry of fluid into the rumen fluid pool was assumed to be $0.020 \mathrm{~L} / \mathrm{h}$, reflecting the fact that the calf did not drink during the experiment, and fluid was being infused into the rumen at a rate of $20 \mathrm{~mL} / \mathrm{h}$. Entry of Co into the Co pool was set at $0.52 \mathrm{mg} / \mathrm{h}$, reflecting the Co infusion rate.
Exit of Co $(\mathrm{mg} / \mathrm{h})$ was calculated by multiplying the Co concentration ( $\mathrm{mg}$ of $\mathrm{Co} / \mathrm{L}$ of rumen volume), at a given time point, by the fluid exit rate $(\mathrm{L} / \mathrm{h})$. The fluid exit rate was equal to a fractional fluid passage rate $\left(\mathrm{h}^{-1}\right)$ multiplied by the fluid volume $(\mathrm{L})$. Initial fluid volume was equal to the fluid volume evacuated from the calf rumen. Because a non-steady state solution needed to be obtained, the fractional fluid passage rate was derived by fitting the modeled Co concentration to the measured Co concentration using the FME package of $\mathrm{R}$ version 3.4.0 (Soetaert and Petzoldt, 2010). A fourth-order Runge Kutta integration algorithm was used to integrate the differential equations describing the $\mathrm{Co}$ and fluid pools, and fitting of the fractional fluid passage rate was done by minimizing the weighted residuals of the model using a Nelder-Mead optimization algorithm.

Suárez et al. (2007) measured the fractional rumen liquid passage rate in 10 -wk-old calves fed diets containing milk replacer and differing amounts of concentrate and roughage and found a rate of liquid passage at

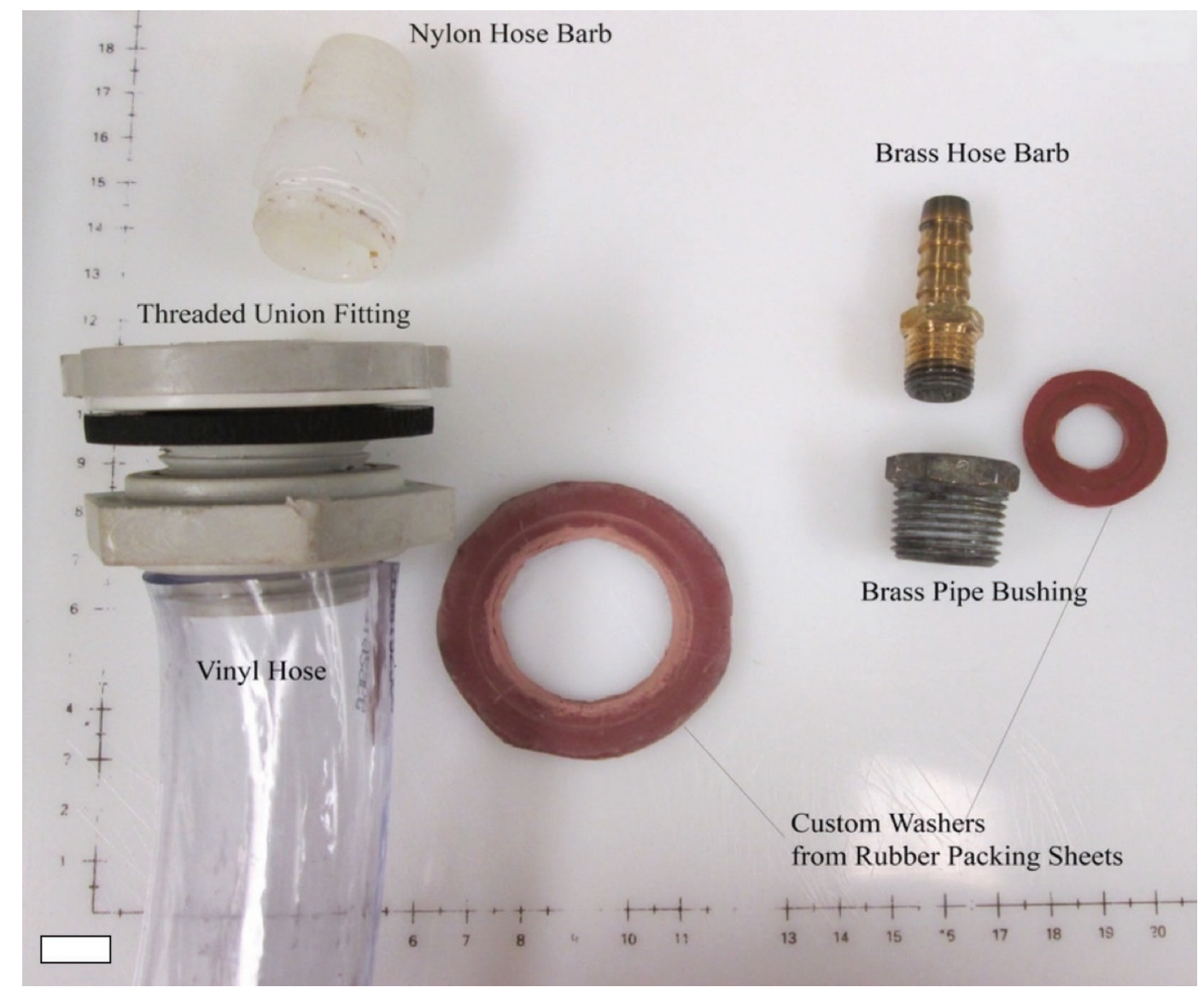

Figure 4. Assembly parts for the custom-made vacuum-assisted collection device used to suction rumen contents from the ruminally cannulated calf. The vinyl hose measured $15.24 \mathrm{~cm}$ and $3.95 \mathrm{~cm}$ o.d. $\times 3.18 \mathrm{~cm}$ i.d. See text for further specifications. White scale bar represents $2 \mathrm{~cm}$. Color version available online. 
Table 1. Fractional rate of rumen liquid passage, rumen content weight, and rumen $\mathrm{pH}$ for an 8-wk-old Holstein calf weighing $80 \mathrm{~kg}$ at sampling, fed a diet of $18 \% \mathrm{CP}$ calf starter and no hay

\begin{tabular}{|c|c|c|c|c|}
\hline Item & $\begin{array}{l}\text { Rate of liquid } \\
\text { passage }^{1}(\% / \mathrm{h})\end{array}$ & $\begin{array}{l}\text { Rumen content } \\
\text { weight (kg) }\end{array}$ & $\begin{array}{c}\text { Rumen } \mathrm{pH} \\
\text { precontent removal }\end{array}$ & $\begin{array}{c}\text { Rumen } \mathrm{pH} \\
\text { postcontent removal }\end{array}$ \\
\hline Calf & 40.2 & 3.15 & 5.62 & 5.60 \\
\hline
\end{tabular}

$46 \% / \mathrm{h}$. The difference in these values may be explained by the nature of Co administration into the rumen, where the current study infused Co directly into the rumen and Suárez et al. (2007) mixed CoEDTA into the milk replacer to assess ruminal drinking. Both of the liquid passage rates estimated in calves $(40.2 \% / \mathrm{h}$ in the present study and 46\%/h in Suárez et al., 2007) are much higher than those found in adult ruminants $(13 \%$ ruminal fluid/h in Seo et al., 2007). The reasoning for the increase in liquid passage rate is not clear, but may be explained by insufficient rumen size to hold large volumes of liquid, thus allowing increased passage of liquid to the rest of the gastrointestinal tract.

After the infusion and sampling protocol was completed, all calf starter was removed from the pen, but the calf had continuous access to water. The goal of this procedure was to verify efficacy of our custom-built vacuum-assisted collection device (Figures 3 and 4) to evacuate typical rumen contents of a young dairy calf for ruminant nutrition experiments. To evacuate the rumen, the cannula plug was removed and the vacuum tube $(183 \mathrm{~cm}$ long and $2.54 \mathrm{~cm}$ o.d. $\times 1.91 \mathrm{~cm}$ i.d.) from a custom-built vacuum device (Figure 3 ) was manually guided into the rumen through the cannula and used to remove rumen contents. For the vacuum device, we connected an 18.93-L bucket to a vacuum pump (model DOA-P704-AA; Gast Manufacturing, Benton Harbor, MI) using a 223-cm long and $1.27 \mathrm{~cm}$ o.d. $\times$ $0.87 \mathrm{~cm}$ i.d. plastic tube. The vacuum trap was created by installing tubing ports in the lid of the bucket. The vacuum out port was built using a brass $0.95 \mathrm{~cm}$ i.d. male hose barb $\times 0.64 \mathrm{~cm}$ male iron pipe, a 0.50 $\mathrm{cm}$ male iron pipe $\times 0.25 \mathrm{~cm}$ female iron pipe brass pipe bushing, and 1 to 2 custom washers cut from rubber packing sheets (Figure 4). The sample in port was built using a nylon $0.64 \mathrm{~cm}$ i.d. $\times 1.91 \mathrm{~cm}$ male iron pipe male hose barb, a nylon 1.91-cm female iron pipe threaded union fitting, 1 custom rubber washer, and a $15.24-\mathrm{cm}$ section of $3.95 \mathrm{~cm}$ o.d. x $3.18 \mathrm{~cm}$ i.d. vinyl hose (Figure 4). The connection between the vacuum out port and the pump was $0.95 \mathrm{~cm}$ i.d. vinyl tubing, and the sample tubing was $1.91 \mathrm{~cm}$ i.d. vinyl (Figure 3 ). Vacuum-assisted removal of rumen contents took approximately $2 \mathrm{~min}$ and ceased when contents were no longer observed exiting through the vacuum tube. Rumen emptiness was confirmed visually by passing an inspection scope (model DE-1012; Volador Technology Co. Ltd., Shenzhen, China) through the rumen cannula and manually maneuvering it throughout the various sacs of the rumen. After removal, rumen contents were weighed $(3.15 \mathrm{~kg})$ and then the rumen was washed using a warm $\left(37^{\circ} \mathrm{C}\right)$ wash buffer adapted from Storm et al. (2011). The use of the wash buffer was for practicing the procedure to be used in future rumen evacuation studies in calves. The buffer contained $106 \mathrm{mM} \mathrm{NaCl}$, $24 \mathrm{~m} M \mathrm{NaHCO}_{3}, 20 \mathrm{~m} M \mathrm{KOH}, 2 \mathrm{~m} M \mathrm{~K}_{2} \mathrm{HPO}_{4}, 1.5$ $\mathrm{mM} \mathrm{CaCl} 2$, and $1.5 \mathrm{mM} \mathrm{MgCl}$ (Storm et al., 2011). The buffer remained in the rumen for $5 \mathrm{~min}$ and was removed via our vacuum device. The original rumen contents were then replaced into the rumen. The entire evacuation, inspection, and washing procedure required 70 min to complete. Rumen content $\mathrm{pH}$ changed from 5.62 , measured when rumen contents were removed, to 5.60 when rumen contents were replaced in the rumen. Evacuated rumen contents represented about $4 \%$ $(3.15 / 80 \mathrm{~kg})$ of the calf's BW, which is slightly lower than what has been reported previously ( 5 to $8 \%$ of BW) in calves between 6 and 8 wk of age (Suárez et al., 2006; Kristensen et al., 2010; Yohe et al., 2015). This difference might be explained by the collection methods used. In the present study we physically evacuated the rumen, whereas other studies have slaughtered calves to be able to measure content in both the rumen and reticulum. Visual inspection of the calf showed no signs of distress during or after the entire evacuation, inspection, and washing procedure. Likewise, even though intake of water and starter was not measured after the procedures took place, we can say that visually intake of water and starter appeared to resume with no problem due to witnessing similar loss of water and starter in the buckets, which indicated minimal effect of the study on the calf's health and well-being.

In conclusion, we demonstrated that our custombuilt infusion and sampling device and the custombuilt vacuum device were effective tools when tested in a 2-mo-old ruminally cannulated calf. Fellow scientists may employ and further modify our techniques to suit their needs when performing nutrition trials in calves. 


\section{ACKNOWLEDGMENTS}

Carrie A. Ceh, a graduate student at Virginia Tech (Blacksburg, VA), helped with calf feeding and care. We thank Mark D. Hanigan for his helpful discussions on ruminal infusion and sampling and vacuum-assisted collection devices in cows. Additionally, R. Michael Akers, Rebecca R. Cockrum, and M. D. Hanigan (Virginia Tech), along with Erin E. Connor (UDSA, Beltsville, MD) served on Yohe's PhD guidance committee and are thanked for providing editorial input on this manuscript.

\section{REFERENCES}

Annison, E. F., R. Bickerstaffe, and J. L. Linzell. 1974. Glucose and fatty-acid metabolism in cows producing milk of low fat content. J. Agric. Sci. 82:87-95.

Azevedo, R. A., F. S. Machado, M. M. Campos, D. R. Lopes, S. F. Costa, H. C. Mantovani, F. C. Lopes, M. I. Marcondes, L. G. Pereira, T. R. Tomich, and S. G. Coelho. 2016. The effects of increasing amounts of milk replacer powder added to whole milk on passage rate, nutrient digestibility, ruminal development, and body composition in dairy calves. J. Dairy Sci. 99:8746-8758.

Conrad, H. R., J. W. Hibbs, and W. D. Pounden. 1956. Absorption of rumen volatile fatty acids from the forestomachs of young dairy calves fed high roughage rations. J. Dairy Sci. 39:97-98.

Dijkstra, J., H. Boer, J. Van Bruchem, M. Bruining, and S. Tamminga. 1993. Absorption of volatile fatty acids from the rumen of lactating dairy cows as influenced by volatile fatty acid concentration, $\mathrm{pH}$ and rumen liquid volume. Br. J. Nutr. 69:385-396.

EPA. 1998. Standard Methods for the Examination of Water and Wastewater. 20th ed. United Book Press, Baltimore, MD.

Gaebel, G., H. Martens, M. Suendermann, and P. Galfi. 1987. The effect of diet, intraruminal $\mathrm{pH}$ and osmolarity on sodium, chloride and magnesium absorption from the temporarily isolated and washed reticulorumen of sheep. Q. J. Exp. Physiol. 72:501-511.

Khouri, R. H. 1969. Absorption of steam volatile fatty acids from reticulorumen of anaesthetised calves. N. Z. J. Agric. Res. 12:299-312.

Kristensen, N. B., M. Engbaek, M. Vestergaard, and D. L. Harmon. 2010. Technical note: Ruminal cannulation technique in young Holstein calves: Effects of cannulation on feed intake, body weight gain, and ruminal development at six weeks of age. J. Dairy Sci. 93:737-742.

Kristensen, N. B., and D. L. Harmon. 2004. Effect of increasing ruminal butyrate absorption on splanchnic metabolism of volatile fatty acids absorbed from the washed reticulorumen of steers. J. Anim. Sci. 82:3549-3559.
Krizsan, S. J., S. Ahvenjarvi, H. Volden, and G. A. Broderick. 2010. Estimation of rumen outflow in dairy cows fed grass silage-based diets by use of reticular sampling as an alternative to sampling from the omasal canal. J. Dairy Sci. 93:1138-1147.

Lesmeister, K. E., and A. J. Heinrichs. 2004. Effects of corn processing on growth characteristics, rumen development, and rumen parameters in neonatal dairy calves. J. Dairy Sci. 87:3439-3450.

NRC. 2001. Nutrient Requirements of Dairy Cattle. 7th ed. Natl. Acad. Press, Washington, DC.

Seo, S., C. Lanzas, L. O. Tedeschi, and D. G. Fox. 2007. Development of a mechanistic model to represent the dynamics of liquid flow out of the rumen and to predict the rate of passage of liquid in dairy cattle. J. Dairy Sci. 90:840-855.

Soetaert, K., and T. Petzoldt. 2010. Inverse modelling, sensitivity and Monte Carlo analysis in $\mathrm{R}$ using package FME. J. Stat. Softw. 33:1-28. https://doi.org/10.18637/jss.v033.i03.

Storm, A. C., M. D. Hanigan, and N. B. Kristensen. 2011. Effects of ruminal ammonia and butyrate concentrations on reticuloruminal epithelial blood flow and volatile fatty acid absorption kinetics under washed reticulorumen conditions in lactating dairy cows. J. Dairy Sci. 94:3980-3994.

Suárez, B. J., C. G. Van Reenen, G. Beldman, J. van Delen, J. Dijkstra, and W. J. Gerrits. 2006. Effects of supplementing concentrates differing in carbohydrate composition in veal calf diets: I. Animal performance and rumen fermentation characteristics. J. Dairy Sci. 89:4365-4375.

Suarez, B. J., C. G. Van Reenen, N. Stockhofe, J. Dijkstra, and W. J. Gerrits. 2007. Effect of roughage source and roughage to concentrate ratio on animal performance and rumen development in veal calves. J. Dairy Sci. 90:2390-2403.

Suárez-Mena, F. X., A. J. Heinrichs, C. M. Jones, T. M. Hill, and J. D. Quigley. 2015. Digestive development in neonatal dairy calves with either whole or ground oats in the calf starter. J. Dairy Sci. 98:3417-3431.

Suárez-Mena, F. X., A. J. Heinrichs, C. M. Jones, T. M. Hill, and J. D. Quigley. 2016. Straw particle size in calf starters: Effects on digestive system development and rumen fermentation. J. Dairy Sci. 99:341-353.

Sutton, J. D., M. S. Dhanoa, S. V. Morant, J. France, D. J. Napper, and E. Schuller. 2003. Rates of production of acetate, propionate, and butyrate in the rumen of lactating dairy cows given normal and low-roughage diets. J. Dairy Sci. 86:3620-3633.

Sutton, J. D., A. D. Mcgilliard, and N. L. Jacobson. 1963. Functional development of rumen mucosa. 1. Absorptive ability. J. Dairy Sci. 46:426-436.

Udén, P., P. E. Colucci, and P. J. Van Soest. 1980. Investigation of chromium, cerium and cobalt as markers in digesta: Rate of passage studies. J. Sci. Food Agric. 31:625-632.

Yohe, T. T., K. M. O'Diam, and K. M. Daniels. 2015. Growth, ruminal measurements, and health characteristics of Holstein bull calves fed an Aspergillus oryzae fermentation extract. J. Dairy Sci. 98:6163-6175. 